\title{
PREDIKSI JUMLAH PENUMPANG KERETA API DENGAN MENGGUNAKAN
}

\section{METODE ARIMA}

\author{
Maria L. Ria ${ }^{(1)}$, Artanti Indrasetianingsih ${ }^{(2)}$ \\ F.MIPA Universitas PGRI Adi Buana Surabaya \\ e-mail: Marialetisia_24@yahoo.co.id
}

\begin{abstract}
ABSTRAK
Kereta api merupakan sub sektor perhubungan darat yang dianggap penting didalam usaha melayani jasa perhubungan masyarakat. Tujuan dari penelitian ini untuk mendapatkan model ARIMA terbaik dan prediksi jumlah penumpang kereta api untuk satu tahun kedepan. Analisis yang digunakan adalah analisis runtun waktu yaitu model ARIMA. Berdasarkan hasil analisis adalah model ARIMA $(1,1,0)(0,1,1)^{12}$, dengan nilai MSE $=551425$, nilai $\mathrm{RMSE}=872,9009$ dan MAPE 9,8\%. Model ARIMA $(1,1,0)(0,1,1)^{12}$ adalah $X_{t}=0,7149 X_{t-1}+0,2851 X_{t-2}+X_{t-12}+X_{t-13}+0,2851 X_{t-13}-0,2851 X_{t-14}+e_{t}-0,8248 e_{t-12}$.

Didapat hasil peramalan jumlah penumpang kereta api dari bulan Maret tahun 2015 hingga bulan Februari tahun 2016. Dari hasil peramalan jumlah penumpang yang tertinggi adalah pada bulan Desember tahun 2015 yaitu 27.134 penumpang

Kata kunci : ARIMA, MAPE, MSE.

\section{ABSTRACT}

Train is a land transportation sub-sectors which is considered important in the effort in serving the society public services. The purpose of this research is to obtain the best ARIMA model and predictions of the number of railway passengers for the coming year. The analysis which is used is the analysis of time series that is ARIMA model. The best model for forecasting the number of passenger trains for the next year based on the results of the analysis are ARIMA $(1,1,0)(0,1,1) 12$, with the value of MSE $=55,142$, the value of RMSE $=872.900$ and MAPE 9, 8\%. Model ARIMA $(1,1,0)(0,1,1) 12$ is

$$
X_{t}=0,7149 X_{t-1}+0,2851 X_{t-2}+X_{t-12}+X_{t-13}+0,2851 X_{t-13}-0,2851 X_{t-14}+e_{t}-0,8248 e_{t-12}
$$
obtained forecasting the number of train passengers from March 2015 until February 2016. From the results of forecasting the highest number of passengers in December 2015 is 27134.3 passengers. Expected from the results of this research will help the company PT Kereta Api in anticipation of the surge of passengers that will occur in future periods.
\end{abstract}

Keywords : ARIMA, MAPE, MSE.

\section{PENDAHULUAN}

Kereta api saat ini telah menjadi salah satu sarana transportasi dalan masyarakat Indonesia untuk melakukan perjalanan jarak jauh dan menengah. Kereta api merupakan sub sector perhubungan darat yang dianggap penting didalam usaha mealayani jasa perhubungan masyarakat. Badan Pusat Statistik (BPS) mencatat jumlah penumpang kereta api angkutan kereta api di jawa dan Sumatra pada bulan November 2012 sebanyak 15,8 juta orang atau turun 7,91\% dibandingkan bulan sebelumnya. Secara kumulatif jumlah penumpang kereta api selama Januari- November 2012 mencapai 186,1 juta orang atau naik 1,95\% dibandingkan periode yang sama tahun 2011 ( 182,5 juta orang). Kenaikan jumlah penumpang terjadi di wilayah Jabodatabek $11,07 \%$, sebaliknya wilayah jawa non-Jabodatabek dan sumatera turun masing-masin $12,02 \%$ dan $16,45 \%$. (http://www.bps.go.id). Penelitian ini menggunakan analisis runtun waktu yang merupakan suatu peramalan yang menggunkan serangkaian pengamatan terhadap suatu peristiwa, kejadian, gejala, atau variabel yang diambil dari waktu ke waktu. Atau dengan kata lain, peramalan yang menggunakan serangkaian data masa lampau. Model peramalannya menggunakan metode ARIMA, karena model ini mampu mewakili deret waktu stasioner maupun nonstasioner. Tujuan dari penelitian ini adalah Untuk menentukan model ARIMA jumlah penumpang kereta api dan untuk mendapatkan hasil

Penulis $^{1}$, Artanti Indrasetianingsih ${ }^{2}$ / J Statistika Vol. 8 No. 1,(2016) 
prediksi jumlah penumpang kereta api untuk 1 (satu) tahun kedepan.

\section{METODE PENELITIAN}

Dalam penelitian yang dilakukan ini menggunakan data sekunder yang didapatkan melalui website BPS Indonesia (http://www.bps.go.id) yang merupakan data bulanan jumlah penumpang kereta api yang ada di pulau jawa periode bulan januari 2006 sampai dengan bulan februari 2015. Sedangkan model analisis statistic yang digunakan adalah model ARIMA

Langkah-langkah yang dilakukan pada analisis model ARIMA adalah sebagai berikut:
a. Deteksi Stasioneritas Data
b. Identifikasi model
c. Pendugaan parameter model
d. Pemeriksaan atau diagnosa model
e. Pemilihan Model Terbaik
f. Tahap Peramalan.

\section{HASIL DAN PEMBAHASAN Deskriptif Statistik}

Analisis deskriptif digunakan untuk melihat karakteristik dari data, yaitu dengan plot time series data.

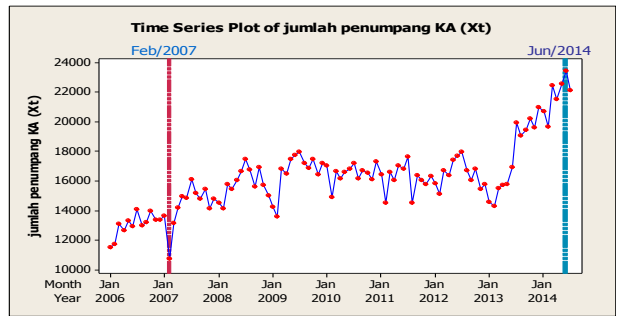

Gambar 3.1. Plot series data jumlah penumpang kereta api

Gambar 3.1 menunjukkan bahwa data jumlah penumpang kereta api dipengaruhi pola trend karena time series plot menunjukkan fluktuasi meningkat. Pada garis merah menandakan jumlah penumpang pada bulan Februari tahun 2007 mengalami penurunan yaitu 10.759 penumpang yang menggunakan jasa transportasi kereta api. Kemudian jumlah penumpang kereta api meningkat pada bulan Juni tahun 2014 yaitu sebanyak 23.415 penumpang yang ditandai dengan garis biru. Sedangkan pada bulan-bulan lainnya jumlah penumpang kereta api relativ stabil. Sehingga dapat disimpulkan bahwa data jumlah penumpang kereta api belum stasioner

Gambar 3.4 plot box-cox transformasi dari data menunjukkan data jumlah penumpang kereta api sudah stasioner dalam varians, terlihat dari nilai batas bawahnya (Lower CL) adalah $-0,18$ dan nilai batas atasnya (Upper CL) yaitu 2,14 yang berada diantara 1, terbukti dengan nilai rounded value (lambda = 1). Untuk menstasionerkan data dalam mean dilakukan differencing yaitu dengan selisih 1 seperti pada gambar 4.5 . Setelah melakukan differencing sebesar 1 data jumlah penumpang kereta api tampak sudah stasioner dalam mean, karena pada grafik 4.5 plot dari differencing data menunjukkan data bergerak di sekitar nilai ratarata.

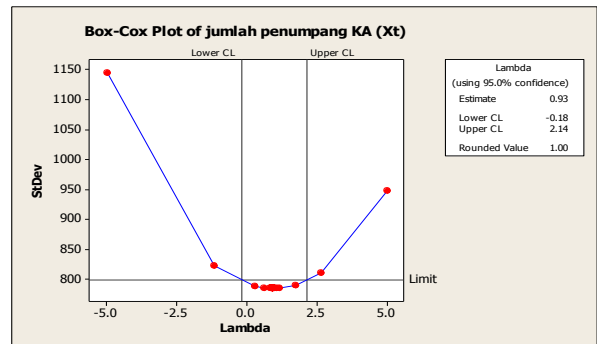

Gambar 3.2. Box-cox transformation Xt

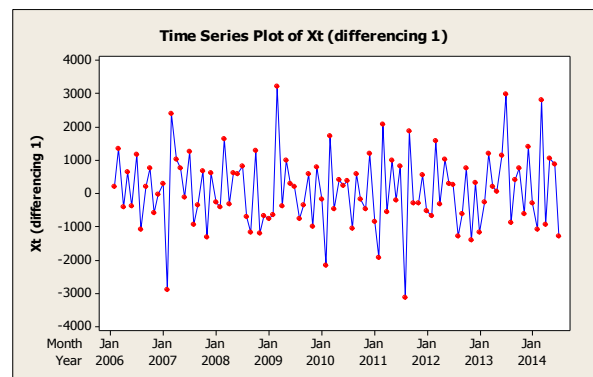

Gambar 3.3. Plot hasil differencing (1)

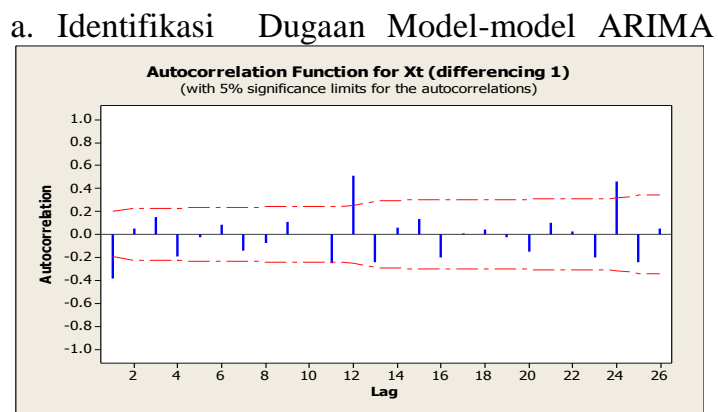

Gambar 3.4. Plot ACF Data Xt (Differencing 1) Non Musiman

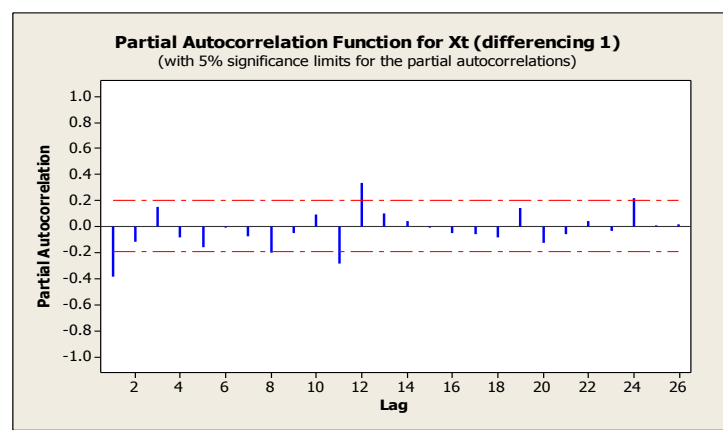


Gambar 3.5. Plot PACF Data Xt (Differencing 1) non musiman

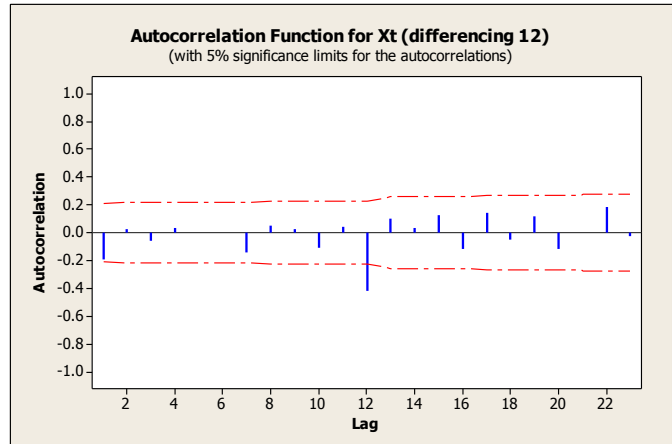

Gambar 3.6. Plot ACF data Xt (differencing 1) musiman

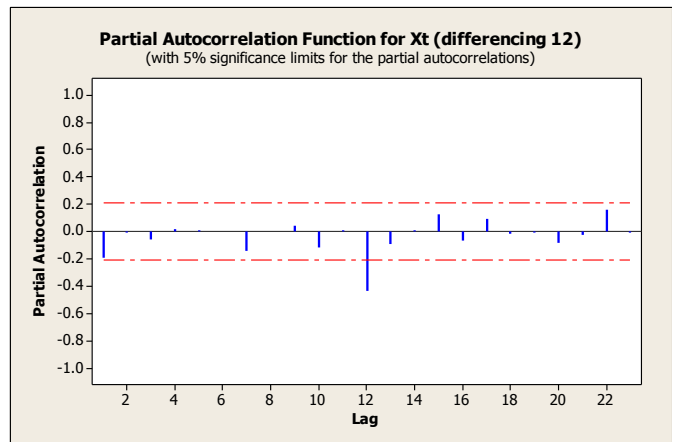

Gambar 3.7. Plot PACF data Xt (differencing 1) musiman

Pada Plot ACF dan PACF pada gambar 3.4 dan gambar 3.7 hasil dari differencing dengan selisih 1 terlihat bahwa ACF terpotong setelah time lag ke-1 sehingga diduga data dibangkitkan oleh MA(1) dan plot PACF dapat dilihat bahwa nilai autokorelasi parsial terpotong pada time lag

\begin{tabular}{|l|c|c|}
\hline \multirow{4}{*}{$\begin{array}{l}\text { Model } \\
\text { ARIMA }\end{array}$} & Lag & p-value \\
\hline \multirow{4}{*}{$(1,1,0)(1,0,0)^{12}$} & & \\
\cline { 2 - 3 } & 12 & 0,387 \\
\cline { 2 - 3 }$(0,1,1)(1,0,0)^{12}$ & 24 & 0,586 \\
\cline { 2 - 3 } & 46 & 0,797 \\
\cline { 2 - 3 } & 12 & 0,810 \\
\cline { 2 - 3 } & 24 & 0,408 \\
\cline { 2 - 3 }$(1,1,0)(1,1,0)^{12}$ & 48 & 0,608 \\
\cline { 2 - 3 } & 12 & 0,833 \\
\cline { 2 - 3 } & 24 & 0,844 \\
\cline { 2 - 3 } & 36 & 0,732 \\
\hline \multirow{3}{*}{$(0,1,1)(1,1,0)^{12}$} & 12 & 0,821 \\
\cline { 2 - 3 } & 24 & 0,868 \\
\cline { 2 - 3 } & 36 & 0,426 \\
\cline { 2 - 3 } & 48 & 0,877 \\
\hline
\end{tabular}

ke-1. Setelah

Penulis $^{1}$, Artanti Indrasetianingsih ${ }^{2}$ / J Statistika Vol. 8 No. 1,(2016) dilakukan differencing pertama menunjukkan adanya faktor musiman dengan periode 12 atau dengan kata lain pola yang terbentuk berulangulang dalam selang waktu 12 bulan. Karena adanya faktor musiman maka perlu dilakukan differencing pertama untuk pola musiman dengan time lag 12, yang hasilnya di tunjukkan pada gambar 3.5 dan gambar 3.6. Dari grafik ACF dan PACF pada gambar 4.8 dan gambar 4.9 terlihat bahwa nilai ACF dan PACF signifikan pada time lag 12.

Dugaan Model ARIMA yang dihasilkan adalah sebagai berikut:
1. $\operatorname{ARIMA}(1,1,0)(1,0,0)^{12}$
2. ARIMA $(0,1,1)(1,0,0)^{12}$
3. ARIMA $(1,1,0)(0,1,1)^{12}$
4. ARIMA $(0,1,1)(0,1,1)^{12}$

b. Estimasi parameter

Berdasarkan dugaan-dugaan model tersebut, maka hasil estimasi parameternya dapat dilihat pada tabel 3.1 dibawah ini

Tabel 3.1. Tabel estimasi parameter model

\begin{tabular}{|c|c|c|c|}
\hline $\begin{array}{c}\text { Model } \\
\text { ARIMA }\end{array}$ & Parameter & Estimasi & $\begin{array}{c}\mathrm{p}- \\
\text { value }\end{array}$ \\
\hline$(1,1,0)(1,0,0)^{12}$ & $\phi_{1}$ & $-0,3255$ & 0,002 \\
\hline & $\Theta_{12}$ & 0,5692 & 0,000 \\
\hline$(0,1,1)(1,0,0)^{12}$ & $\phi_{1}$ & 0,3030 & 0,003 \\
\hline & $\Theta_{12}$ & 0,5848 & 0,000 \\
\hline$(1,1,0)(0,1,1)^{12}$ & $\phi_{1}$ & $-0,2851$ & 0,011 \\
\hline & $\Theta_{12}$ & 0,8248 & 0,000 \\
\hline$(0,1,1)(0,1,1)^{12}$ & $\phi_{1}$ & 0,2624 & 0,018 \\
\hline & $\Theta_{12}$ & 0,8724 & 0,000 \\
\hline
\end{tabular}

Setelah didapat model-model ARIMA yang mungkin, langkah selanjutnya adalah mengestimasi parameternya. Tabel estimasi parameter model ARIMA diatas nilai konstanta dari model tidak dimasukan karena nilai konstantanya tidak signifikan. Tabel 3.1 menunjukkan nilai $\mathrm{p}$-value dari setiap modelmodel telah signifikan karena sudah lebih kecil dari niali $\alpha$ yaitu $5 \%(\mathrm{P}-$ Value $<\alpha)$.

Pada tabel 3.2 uji Ljung-Box diatas terlihat bahwa nilai residual dari setiap model tersebut sudah white noise karena pada setiap lag nilai probabilitasnya tidak signifikan atau lebih besar daripada nilai $\alpha$.

Tabel 3.2. Tabel uji Ljung-Box Residual 
Tabel 3.4. Tabel Pemilihan Model Terbaik

Dan didapatkan model dari ARIMA $(1,10)(0,1,1)$ adalah sebagai berikut

\begin{tabular}{|l|c|c|}
\hline \multicolumn{2}{|l|}{$\begin{array}{c}\text { Asumsi residual \& } \\
\text { kriteria model } \\
\text { terbaik }\end{array}$} & \multicolumn{2}{|c|}{ Model ARIMA } \\
\hline $\begin{array}{l}\text { a. Asumsi } \\
\text { Residual }\end{array}$ & & \\
\hline White noise & $\checkmark$ & $\checkmark$ \\
\hline $\begin{array}{l}\text { Berdistribusi } \\
\text { normal }\end{array}$ & $\checkmark$ & $\checkmark$ \\
\hline b. Perbandingan & & \\
\hline in-Sample & & \\
\hline MSE & 551425 & 529366 \\
\hline out-Sample & & \\
\hline RMSE & 87,290 & 91,578 \\
\hline MAPE & 9,8 & 10,6 \\
\hline
\end{tabular}

Untuk melihat kenormalan pada model dapat dilihat pada tabel 3.3 uji kolmogorov snorv menunjukkan bahwa model ARIMA $(1,1,0)(1,0,0)^{12}$ dan ARIMA $(0,1,1)(1,0,0)^{12}$ tidak berdistribusi normal karena nilai p-value dari model kurang dari 0,05 yaitu sebesar <0,010 dan 0,019. Sedangkan model ARIMA $(1,1,0)(0,1,1)^{12}$ dan ARIMA $(0,1,1)(0,1,1)^{12}$ berdistribusi normal sebab nilai probabilitasnya lebih besar dari 0,05 yaitu sebesar $>0,150$.

Tabel 3.3. Tabel Uji Kolmogorov-Snorv Residual

\begin{tabular}{|l|l|}
\hline $\begin{array}{l}\text { Model } \\
\text { ARIMA }\end{array}$ & P-value \\
\hline$(1,1,0)(1,0,0)^{12}$ & $<0,010$ \\
\hline$(0,1,1)(1,0,0)^{12}$ & 0,019 \\
\hline$(1,1,0)(0,1,1)^{12}$ & $>0,150$ \\
\hline$(0,1,1)(0,1,1)^{12}$ & $>0,150$ \\
\hline
\end{tabular}

Tahap selanjutnya adalah memilih model yang terbaik dengan melihat nilai MSE pada insampel dan RMSE serta MAPE pada out-sampel. Pada tabel 4.5 tampak bahwa model ARIMA $(1,1,0)(0,1,1)^{12}$ memiliki nilai rata-rata standar error sebesar 551425 sedangkan nilai RMSE dan MAPE pada out-sampelnya adalah 87,290 dan 9,8 . Nilai MS, RMSE dan MAPE pada model ARIMA $(0,1,1)(0,1,1)^{12}$ adalah sebesar 529366, 91,578 dan 10,6 , maka model yang cocok untuk digunakan dalam peramalan jumlah penumpang kereta api selama periode waktu 1 (satu) tahun kedepan adalah ARIMA $(1,1,0)(0,1,1)^{12}$ dilihat dari nilai RMSE dan MAPE pada out-sampel yang lebih kecil daripada model ARIMA

$$
\begin{aligned}
X_{t}= & \left(1+(-0,2851) X_{t-1}-0,2851 X_{t-2}+X_{t-12}-(1-0,2851) X_{t-13}\right. \\
& +0,2851 X_{t-14}+e_{t}-0,8248 e_{t-12} \\
& (1,1,0)(0,1,1)^{12} \text { untuk } 12 \text { bulan kedepan }
\end{aligned}
$$

Tabel. 3.5. Peramalan model ARIMA

\begin{tabular}{|c|c|c|c|c|}
\hline Bulan & Aktual & $\begin{array}{c}\% \\
\text { kenaikan } \\
\text { Jumlah } \\
\text { Penumpa } \\
\text { ng Kereta } \\
\text { Api } \\
\end{array}$ & $\begin{array}{c}\text { Ramal } \\
\text { an }\end{array}$ & $\begin{array}{c}\% \\
\text { kenaikan } \\
\text { Jumlah } \\
\text { Penumpan } \\
\text { g Kereta } \\
\text { Api }\end{array}$ \\
\hline Maret & 22.427 & $-4,1 \%$ & 24.723 & $-1 \%$ \\
\hline April & 21.502 & $4,9 \%$ & 24.464 & $3,30 \%$ \\
\hline Mei & 22.547 & $3,8 \%$ & 25.280 & $2 \%$ \\
\hline Juni & 23.415 & $-5,5 \%$ & 25.798 & $3,40 \%$ \\
\hline Juli & 22.125 & $2,9 \%$ & 26.670 & $-3,20 \%$ \\
\hline Agustus & 22.763 & $2 \%$ & 25.824 & $1,10 \%$ \\
\hline September & 23.219 & $5,5 \%$ & 26.116 & $2,90 \%$ \\
\hline Oktober & 24.503 & $-2,1 \%$ & 26.874 & $-2,60 \%$ \\
\hline November & 23.986 & $7,5 \%$ & 26.185 & $3,60 \%$ \\
\hline Desember & 25.791 & $-6 \%$ & 27.134 & $-2,30 \%$ \\
\hline Januari & 24.254 & $-7,7 \%$ & 26.519 & $-4 \%$ \\
\hline \multirow[t]{2}{*}{ Februari } & 22.394 & & 25.446 & \\
\hline & & $1.30 \%$ & & $3,30 \%$ \\
\hline \multicolumn{5}{|c|}{$\begin{array}{l}\text { ersentase jumlah penumpang pada periode } \\
\text { hendatang, menunjukkan bahwa jumlah } \\
\text { enumpang kereta api mengalami kenaikan } 2 \% \text {, } \\
\text { ada data aktual jumlah penumpang kereta api dari } \\
\text { ulan maret } 2014 \text { sampai dengan bulan Februari } \\
015 \text { Tabel }\end{array}$} \\
\hline
\end{tabular}

Berdasarkan tabel 3.5 yang merupakan tabel data aktual dengan data hasil ramalan serta 
penumpang kereta api untuk 1 (satu) tahun kedepan yaitu dari bulan Maret 2015 sampai bulan Februari 2016 menjadi 3,30\% penumpang.

\section{KESIMPULAN DAN SARAN Kesimpulan}

Dari hasil penelitian dan pembahasan dapat di simpulkan bahwa:

1. Analisis model time series yang terbaik untuk melakukan peramalan jumlah penumpang kereta api yang ada di pulau jawa diperoleh model ARIMA $(1,1,0)(0,1,1) 12$, karena memiliki nilai RMSE terkecil dan nilai MAPE dibawah $10 \%$ yaitu $9,8 \%$ dibandingkan model yang lainnya. Model yang di dapat dari ARIMA $(1,1,0)(0,1,1) 12$ sebagai berikut

$$
\begin{aligned}
& X_{t}=0,7149 X_{t-1}-0,2851 X_{t-2}+X_{t-12} \\
& \quad-0,7149 X_{t-13}+0,2851 X_{t-14}+e_{t}-0,8248 e_{t-12}
\end{aligned}
$$

2. Model ARIMA Box-Jenkins diperoleh nilai ramalan untuk 1 (satu) tahun kedepan adalah

$\begin{array}{ll}\text { Bulan } & \text { Ramalan } \\ \text { Maret /2015 } & 24.723 \\ \text { April /2015 } & 24.464 \\ \text { Mei /2015 } & 25.280 \\ \text { Juni /2015 } & 25.798 \\ \text { Juli /2015 } & 26.670 \\ \text { Agustus /2015 } & 25.824 \\ \text { September/2015 } & 26.116 \\ \text { Oktober/2015 } & 26.874 \\ \text { November/2015 } & 26.185 \\ \text { Desesmber/2015 } & 27.134 \\ \text { Januari/2016 } & 26.519 \\ \text { Februari/2016 } & 25.446\end{array}$

\section{Saran}

Saran yang dapat diberikan sesuai dengan peramalan ini adalah sesuai dengan hasil peramalan jumlah penumpang kereta api, bisa menjadi pertimbangan bagi PT Kereta Api Indonesia (Persero) agar dapat melakukan tindakan antisipasi yaitu dengan cara menambah fasilitas kereta api seiring dengan meningkatnya jumlah penumpang kereta api.

\section{DAFTAR PUSTAKA}

Hadi, S. 2000. Metodologi Research. Yogyakarta:Andi Offset

Makridarkis, S., S. C. Wheelwright, and V. E. Mc Gee. 1993. Metode dan Aplikasi Peramalan. Jilid I. Edisi ke-2. Erlangga. Jakarta. Diterjemahkan oleh Untung Sus Andriyanto dan Abdul Basith. Hlm 391-491.

Miro, Fidel.2005. Pengantar Sistem Transportasi.Erlangga .Jakarta

Nasution, M. N. 2002. Manajemen Transportasi. Edisi ke-2. Ghalia Indonesia. Jakarta. Hlm 70-72.

Nazir.Moh.1988.Metode Penelitian. Jakarta: Ghalia Indonesia

Sandik,R.(2003). Analisis Deret Waktu Untuk Meramalkan Jumlah Penumpang Kereta Api Matarmaja Jurusan Tulungagung. Surabaya: Institut Teknologi Sepuluh Nopember

Soejoeti, Zanzawi. 1987. Materi Pokok Analisis Runtun Waktu. Jakarta: Karunika.

Sudjana. (1986). Metode Statistika. Bandung: Tarsito.

Subagyo, P. 2003. Statistik Deskriptif. BPFE. Yogyakarta. Hlm 97-114.

Susanto,Hari.(2009).Diaksesdarihttp://haribogel.bl ogspot.com/2009/02/kereta-api.html.Hari Senin,14April2015

Salamah, M., Suhartono, dan Sri P.W. 2003. Analisis Time Series. Fakultas Matematika dan Ilmu Pengetahuan Alam Lembaga Penelitian Institut teknologi Sepuluh Nopember. Surabaya.

Wei, W. 2006. Time Series Analysis. Canada: Addison-Wesley Publishing Company. http://www.bps.go.id/linkTabelStatis/view/id/1417 . tanggal unduh 20 April 2015 
